\title{
Forensic Investigation of Fire-affected Reinforced Concrete Buildings
}

\author{
Awoyera, P.O. ${ }^{1}$, Akinwumi, I.I. ${ }^{2}$, Ede, A.N. ${ }^{3}$, Olofinnade, M.O. ${ }^{4}$ \\ 1,2,3,4 (Department of Civil Engineering, College of Science and Technology/ Covenant University, Nigeria)
}

\begin{abstract}
This study focused on forensic investigation of fire-affected reinforced concrete buildings. Post-fire investigation was conducted on structural elements in three selected fire-affected concrete buildings, in order to ascertain their in situ residual strengths and also to provide data for use in future assessment of fire-affected buildings. The selected sites for investigation include a five-storey building at Alagbaka and a bungalow at Adegbola in Akure, and a ten-storey building in Benin, Nigeria. Rebound hammer and ultrasonic pulse velocity are two non-destructive tests apparatus used for this investigation. Average values of pulse velocity were fitted into an established model in order to estimate the probable temperature, which the buildings were subjected to. Tests were conducted on beams, columns and slabs in both the affected and the unaffected parts of the buildings. From the results, visual examination of the fire-affected buildings revealed changes in the colour of the concrete, delamination of plaster of slab and exposure of reinforcement for severe cases at various locations on the concrete members. In addition, there was notable reduction in the in situ strengths of the fire-affected structural members when compared with the unaffected members. It was deduced that concrete members subjected to temperatures above $600^{\circ} \mathrm{C}$ lost about $70 \%$ of its strength.
\end{abstract}

Keywords: concrete, fire, nondestructive test, reinforcement, temperature

\section{Introduction}

Over the years, many fire incidents have occurred in public places due to some unforeseen circumstances such as the use of explosives, ethnic crises, and accidents. However, there is eminent need for buildings, tunnels and many other concrete infrastructures to be assessed for inherent residual strength and changes in physical appearance following fire incidents. After a severe fire, structures could be repaired rather than being demolished. Many fire-affected buildings in Nigeria in recent years have been demolished while some others are left dilapidated; consequently there is a persistent requirement for structures to be forensically assessed after fire damage to ensure safety and enable appropriate repairs to be planned and implemented. It is necessary to evaluate fire-affected structures in a systematic manner to determine the extent of damage, and in order to propose appropriate repairs or reconstruction. According to [1], the intensity and duration of fire can be estimated by observing the damage; a variety of testing methods and tools are available to evaluate the effects of fire on both the materials and structural elements. These evaluations, combined with an engineering analysis, allow effective and economical repair details to be developed and installed as needed.

[2], while describing the procedures for assessment, design and repair of fire-damaged structures, stated that it consists of preliminary inspection, assessment of damage, testing and detailed assessment, design of repairs to structural elements and implementation of structural repairs.

Influence of fire on concrete and their embedded reinforcements cannot be under estimated, even though concrete cover provide some protection to the latter. [3], investigated the significance of concrete cover to reinforcement in structural element at varying temperatures, it was revealed that the average ultimate tensile strength of steel decreased from $592.0 \mathrm{~N} / \mathrm{mm}^{2}$ at $30^{\circ} \mathrm{C}\left(86^{\circ} \mathrm{F}\right)$ to $300.97 \mathrm{~N} / \mathrm{mm}^{2}$ at $700^{\circ} \mathrm{C}\left(1292^{\circ} \mathrm{F}\right)$ for concrete beam with $20 \mathrm{~mm}$ cover; representing a loss in strength of the steel by $49.2 \%$. The variation of ultrasonic pulse velocity (UPV) with temperature in concrete beams was studied by [4], their investigation revealed that UPV decreases with increasing temperature. According to [5], compressive strength is one of the prime qualities by which concrete is judged; it is probably the most investigated property at high temperatures. The residual strength of a fire-damaged concrete structure has to be determined in order to make decisions for renovation work. [6] revealed that corrosion in concrete is the most serious and commonly encountered durability problem mostly after fire. Corrosion can crack the concrete cover and make it spall and it could also reduce the area of steel embedded in it. Several other defects emanates during fire occurrence in concrete structures. This study is aimed at forensic investigation of fire-affected reinforced concrete structures, the tests conducted entails visual inspection to check defects on the concrete and also rebound hammer and ultrasonic pulse velocity tests which was used to estimate the residual strength of the structural members. 


\section{Nondestructive Testing}

Nondestructive test (NDT) methods are increasingly applied for the investigation of concrete structures. [7], described NDT as a method of test that does not impair the intended performance of the element or member under investigation. It could be done during and after construction, in-service or maintenance. These tests are conducted during construction in order to ensure quality control and monitoring of strength in fresh concrete works and also existing structures to establish their structural adequacy and material deterioration against time or environment. Although standard control cubes are used to determine the strength of concrete produced on site, they cannot be true representative of the in situ concrete in a structure [8]. Extraction and testing of cores taken from the concrete structure is another option available to an investigator. However, extraction of cores is expensive and might weaken the structure [8]. Researchers have therefore devised various NDT methods that enable certain properties of concrete to be measured in situ, from which an estimate of concrete strength may be made. Most used NDT methods in concrete structures include visual inspection, Schmidt or rebound hammer test and the UPV test. According to [9], the range of properties that can be assessed using NDT and partially destructive tests is quite large and includes such fundamental parameters as density, elastic modulus and strength as well as surface hardness and surface absorption, and reinforcement location, size and distance from the surface. Figures 2a-c described the various recommended positioning of the transmitting and the receiving transducers while using the UPV tester, also figure 3 shows a cutaway schematic view of the Schmidt or rebound hammer. Tables 1 and 2 shows the interpretation of the UPV and rebound hammer umber $(\mathrm{RHN})$ results respectively with the quality of concrete given by [10][11].

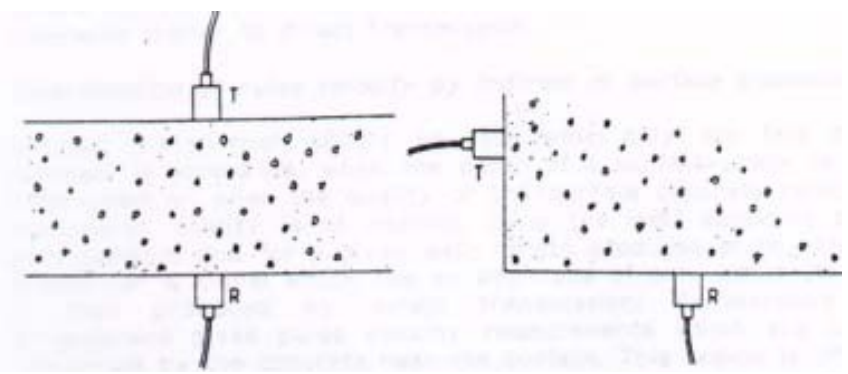

Fig.2a Direct Transmission [9]

fig.2b Semi-Direct Transmission [9]

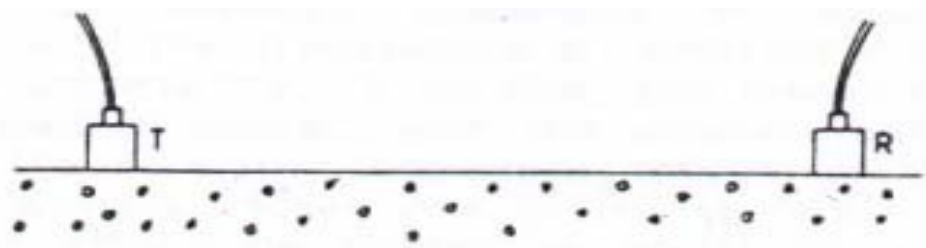

Fig.2c Indirect Transmission [9]

Key: $\mathrm{T}$ - Transmitter, $\mathrm{R}$ - Receiver

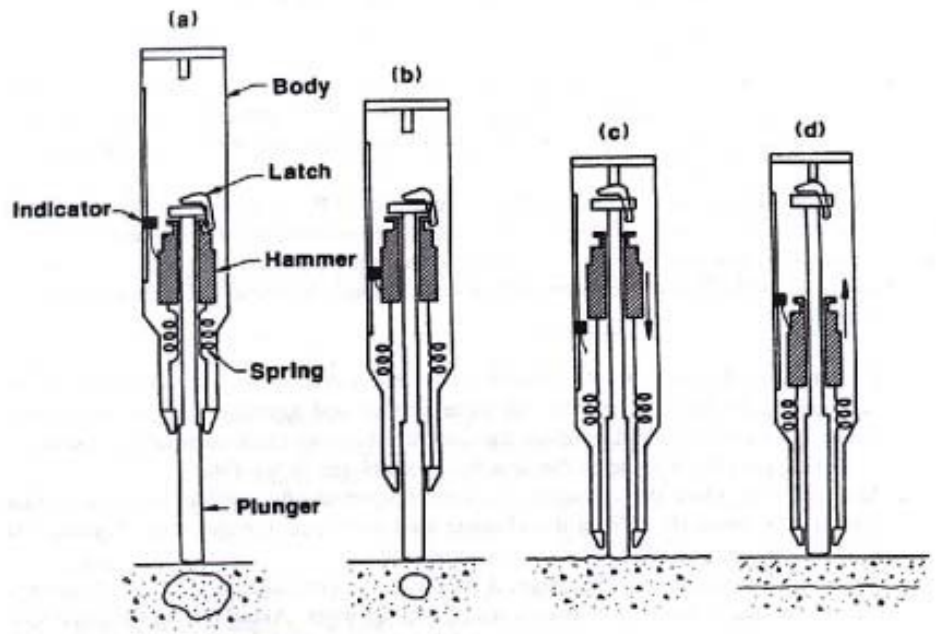

Fig.3. Cutaway Schematic View of the Schmidt Rebound Hammer [9] 
Table 1: Quality of concrete given by [10] as a function of UPV

\begin{tabular}{ll}
\hline UPV $(\mathrm{Km} / \mathrm{s})$ & Concrete Quality \\
\hline Above 4.5 & Excellent \\
$3.5-4.5$ & Good \\
$3-3.5$ & Medium \\
Below 3 & Doubtful \\
\hline
\end{tabular}

Table 2: Quality of concrete given by [11] as a function of RHN

\begin{tabular}{ll}
\hline Average RHN & Concrete Quality \\
\hline Above 40 & Excellent \\
$30-40$ & Good \\
$20-30$ & Fair \\
below 20 & Poor/Delaminated \\
0 & Very Poor \\
\hline
\end{tabular}

III. Materials And Methods

The equipment and tools used for this research work include the following:

N- Type Schmidt Rebound Hammer,

Pundit 6 Ultrasonic Pulse Tester, and

Kodak C140 Digital Camera.

Prior to the testing of the concrete structures, digital camera was used to take photographs for the purpose of cataloguing the physical changes in properties of the fire-affected parts of the concrete buildings under investigation with respect to the unaffected parts of the buildings. Subsequently, NDTs were conducted on slab panels, beams and columns within the fire-affected parts as well as in the unaffected parts using the Schmidt or rebound hammer and the ultrasonic pulse tester. These tests were carried out in accordance with the requirements of [10], [11] and [12]. The rebound numbers and pulse velocity values were noted at designated points, however, coring of concrete was not permitted by the building owners.

\subsection{Case Study Sites}

The selected sites for investigation includes a five-storey building at Alagbaka and a bungalow at Adegbola, both in Akure, and a ten-storey building in Benin, Nigeria. These sites are represented as A, B, and C respectively. Sites A and C were more severely damaged. At site A, only the fourth floor was affected therefore the obtained result in unaffected third floor was used for its result comparison. Also, at site $\mathrm{C}$, the eighth and ninth floors were affected meanwhile the result obtained for the unaffected sixth floor was used for comparison. It was revealed by the building owners that they were recently damaged by fire.

\subsection{Testing}

Using the rebound hammer, a series of 15 readings were taken on slab panels, beams and columns in a diamond pattern at test points as recommended in [11]. Also using the UPV tester three different readings were obtained for slab panels using the semi-direct transmission procedure as recommended in [10]. Whereas, for beams and columns, three different readings were obtained using the direct transmission procedure as recommended in [10].

In the test described in [10], that the time the pulses take to travel through concrete is recorded. Then, the pulse velocity is computed as:

$v=\frac{2}{\tau}$

where $\mathrm{V}=$ pulse velocity $(\mathrm{m} / \mathrm{s}), \mathrm{L}=$ length $(\mathrm{m})$, and $\mathrm{T}=$ Transit Time $(\mathrm{s})$, which is equal to the travel time between the transmitting and receiving transducers when they are pressed firmly together. Figure 4 shows the UPV tester used. 


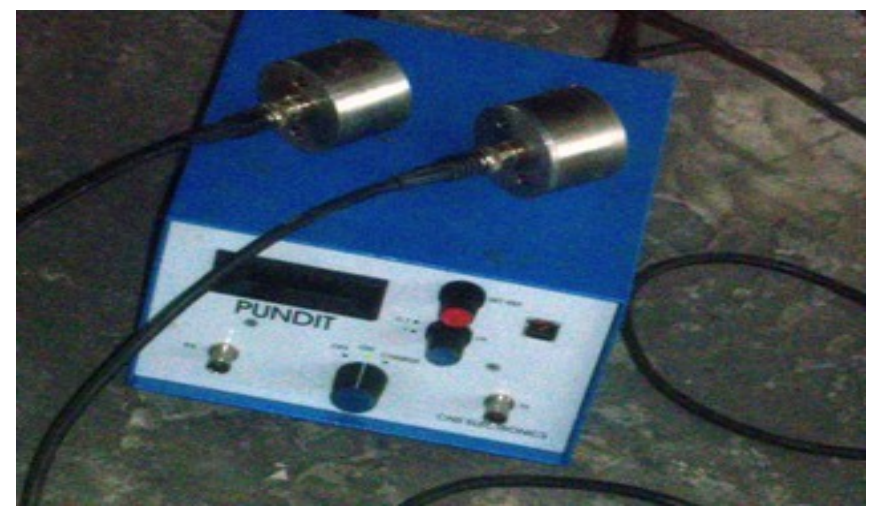

Fig. 4: Pundit Ultrasonic pulse tester Used for the Investigation

In addition, photographs of the various defects observed on the fire-affected concrete surface are also presented. Figures 5(a-d) shows various surface defects observed on some of the fire-affected members.

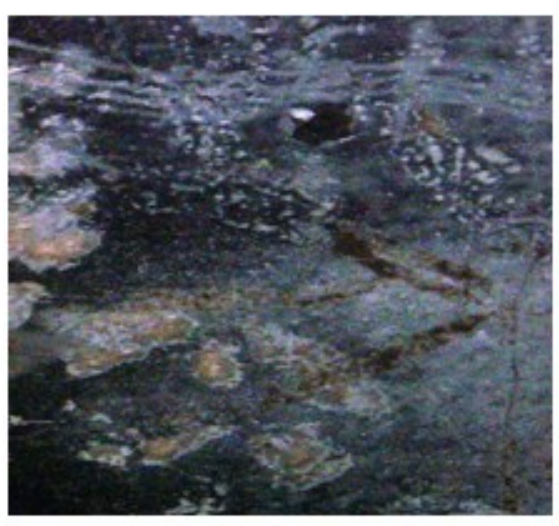

Fig. 5a: Spalled concrete surface

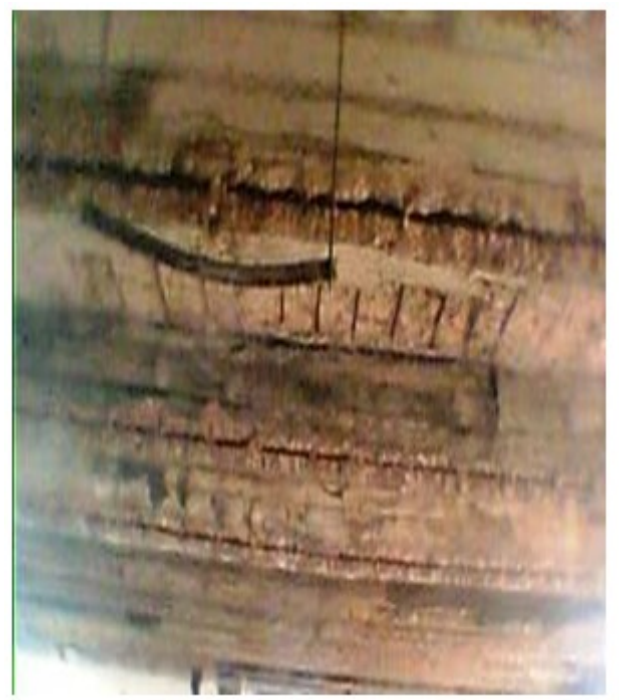

Fig 5c: Exposed reinforcement in slab and beams

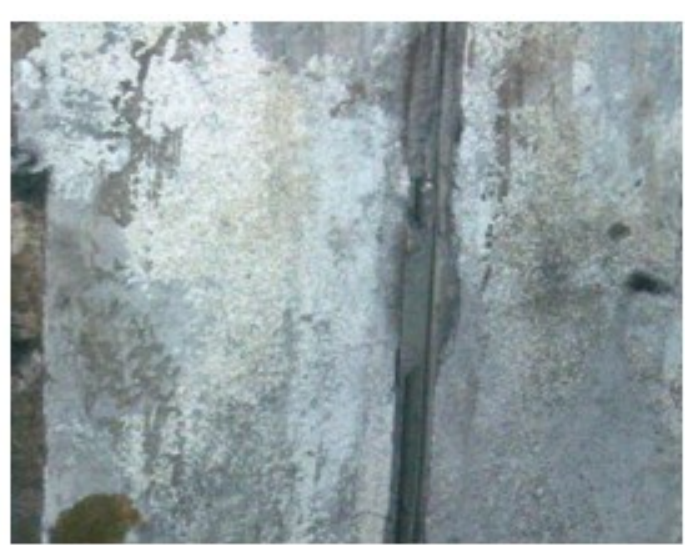

Fig. 5b: Blemished concrete surface

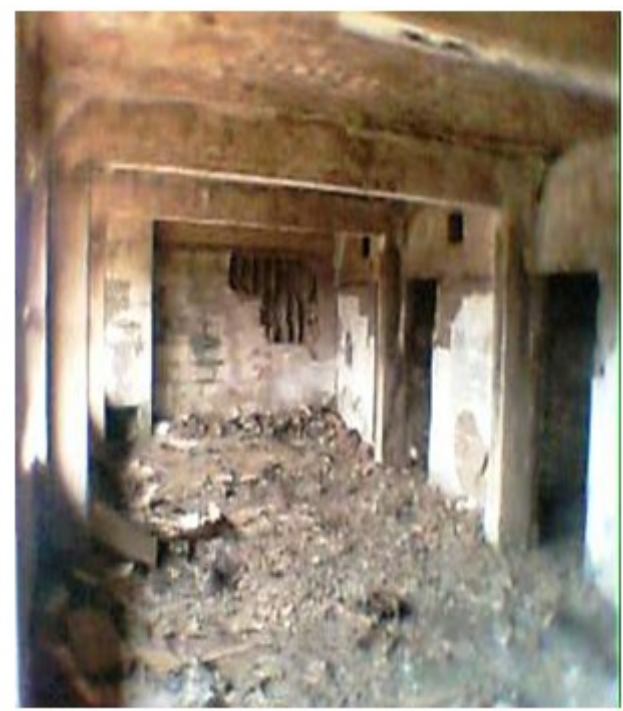

Fig. 5d: Delaminated slabs, beams and columns

Before conducting the rebound hammer and the pulse velocity tests, the surface of the members under investigation were systematically prepared. The surface were smoothened in all cases but for UPV test, grease was applied as couplant to enhance adequate contact between the concrete and the transducers. Figures 6(a-d) show the processes of tests conducted on structural members in the building sites. 


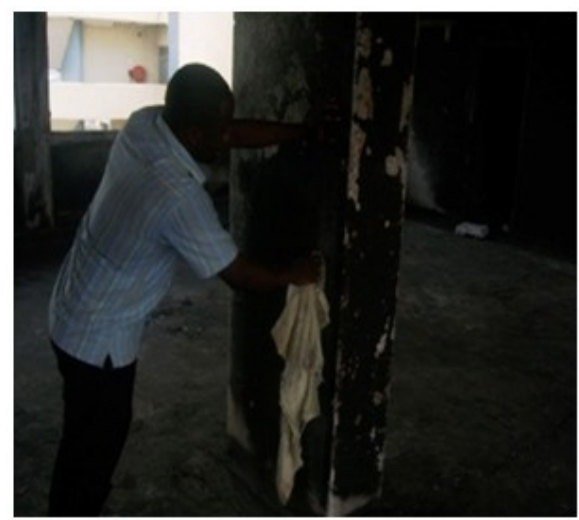

Fig. 6a: Smoothening of the surface to be tested

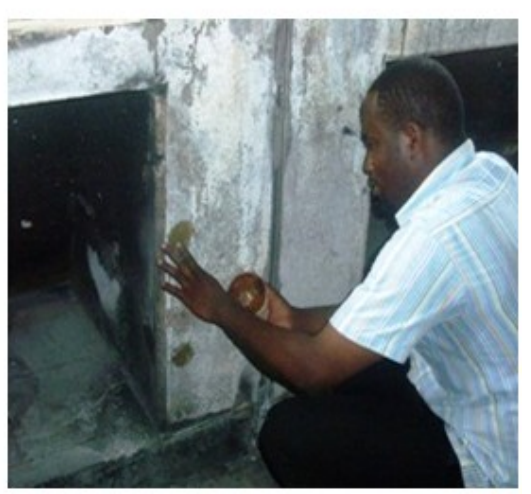

Fig.6b: Grease applied to surface to be tested

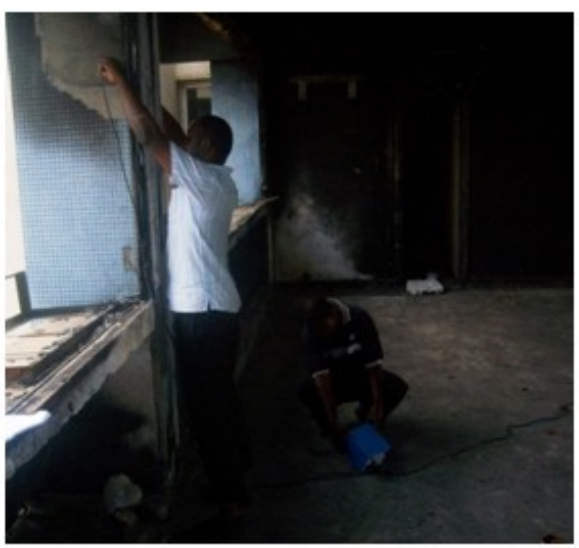

Fig. 6c: UPV test on column

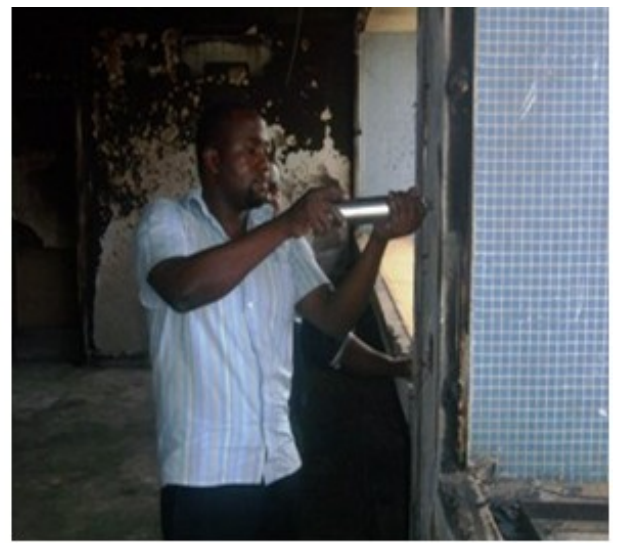

Fig. 6d: RH test on column

\section{Results And Discussion}

The observed defects on the surfaces of the concrete coupled with the average hammer number and pulse velocity obtained at test points were utilized to evaluate the quality and residual strength of the concrete. Table 3 summarizes the observed physical changes on the concrete and the probable temperature attained in the investigated buildings. Using an established model by [4], the probable temperature at which the buildings had been subjected were estimated.

The model states thus;

$y=-0.005 x+4.457$

where $\mathrm{y}$ is UPV value in $\mathrm{km} / \mathrm{s}$ and,

$\mathrm{x}$ is temperature in ${ }^{0} \mathrm{C}$

Using the average UPV and RHN results obtained for site A, it was deduced that the fire-affected part of the building lost $26-40 \%$ of its strength. The model used for estimating the temperature revealed that the building might have been subjected to a temperature range of $280^{\circ} \mathrm{C}-450^{\circ} \mathrm{C}$. Figure 7 shows the result of NDT conducted at Site A. More so, the observed physical defects on the building includes spalling and blemishes on concrete surface, cracks and delamination of plaster of slab in some areas, fig. (5a and 5b). Considering the BS [10], [11] and [12] recommendation for NDT, It was deduced that the affected concrete members are still good but requires plastering. Site B concrete elements were not as affected by fire as those at site A, in that, only about $30 \%$ of the strength was lost which occurred at a suggested temperature range of $250^{\circ} \mathrm{C}-350^{\circ} \mathrm{C}$.

Observed physical changes include dark and whitish colour due to smoke and some instance of cracks. The NDT results obtained indicated that the concrete members are still good for use but only requires adequate renovation. Figure 8 shows the result of NDT conducted on site B.

Site $\mathrm{C}$ was the most severely affected by fire, most especially at the ninth floor where about $70 \%$ of strength of members were lost. This part of the building might have been subjected to temperature range of $600^{\circ} \mathrm{C}$ and above. The strength loss in the concrete members at the ninth floor was so affected by the fire that members were vibrating during testing. It is an indication that concrete elements subjected to temperature above $600^{\circ} \mathrm{C}$ are to be considered not useful. However, in the eighth floor, strength loss in the members was about $20-$ $30 \%$. This part of the building might have been subjected to temperature range of $250^{\circ}-350^{\circ} \mathrm{C}$. Moreover, 
changes observed in the physical appearance of the concrete surface includes; removal of concrete cover in beams and slabs which exposed reinforcements and aggregates, pop-out and delamination of concrete in slabs, beams and columns. Figures $5 \mathrm{c}$ and $5 \mathrm{~d}$ shows the defects observed at the site $\mathrm{C}$ and figure 9 shows the result of the NDT conducted at site $\mathrm{C}$.

Table 3: Changes in Properties of Fire-affected buildings

\begin{tabular}{|c|c|l|c|}
\hline S/N & Building & \multicolumn{1}{|c|}{ Concrete Surface Appearance } & Probable Temperature Attained \\
\hline 1 & Site A & $\begin{array}{l}\text { spalled \& blemished concrete surface, cracks } \\
\text { and delamination of plaster of slab in some } \\
\text { areas. }\end{array}$ & $280{ }^{\circ} \mathrm{C}-450{ }^{\circ} \mathrm{C}$ \\
\hline 2 & Site B & $\begin{array}{l}\text { Dark \& whitish colour due to smoke, some } \\
\text { instance of cracks }\end{array}$ & $250^{\circ} \mathrm{C}-350^{\circ} \mathrm{C}$ \\
\hline 3 & Site C & $\begin{array}{l}\text { Removal of concrete cover in in } \\
\text { beams \& slabs where reinforcements \& } \\
\text { aggregates are exposed, pop-out and } \\
\text { delamination of concrete in Slabs, beams \& } \\
\text { columns }\end{array}$ & $\begin{array}{l}60{ }^{\circ} \mathrm{C} \text { above in the } 9^{\text {th }} \text { floor, } \\
2500^{\circ} \mathrm{C}-350^{\circ} \mathrm{C} \text { in the } 8^{\text {th }} \text { floor }\end{array}$ \\
\hline
\end{tabular}

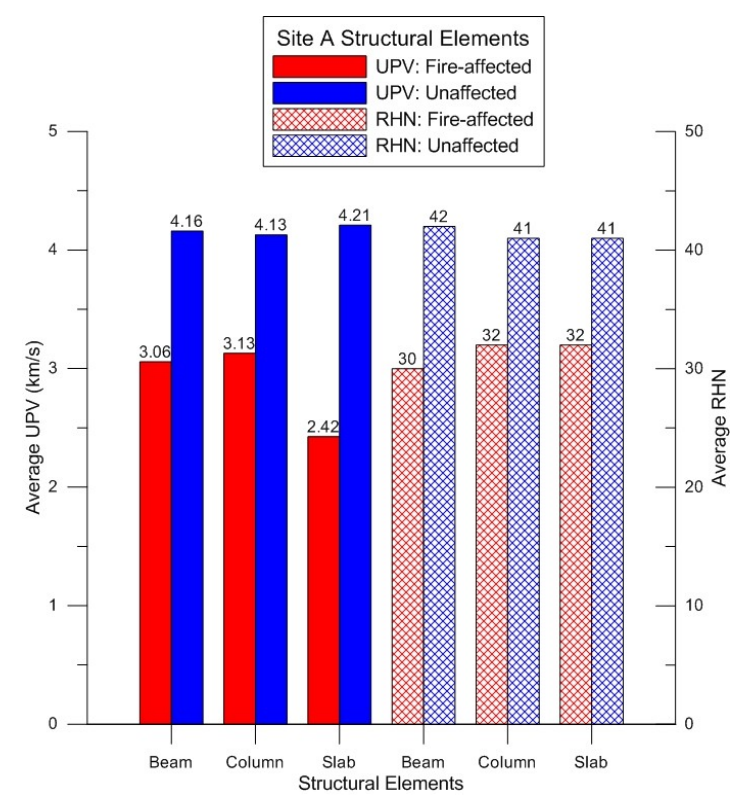

Fig. 7. Nondestructive Test Results for Site A

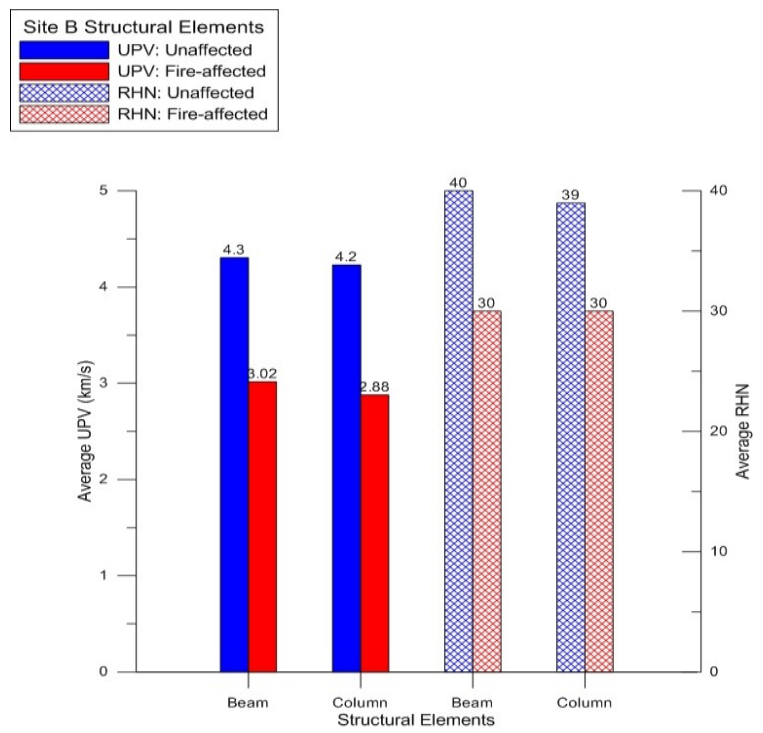

Fig. 8. Nondestructive Test Results for Site B 


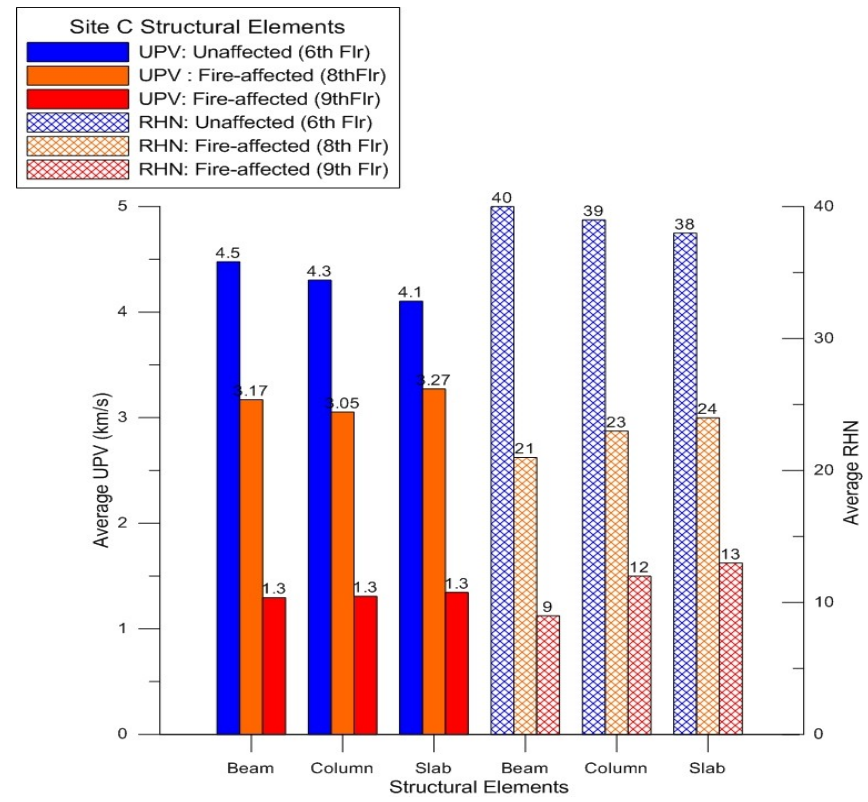

Fig.9. Nondestructive Test Results for Site C

\section{Conclusion}

From the results of NDT tests conducted on members and the surface defects catalogued in the selected sites, the following conclusions can be drawn:

1) Concrete elements subjected to temperature up to $450^{\circ} \mathrm{C}$ or $500^{\circ} \mathrm{C}$ are still safe for use because at this temperature concrete moistures would have been absolved by fire and cracks will occur due to expansion and contraction of constituent materials but the entire structure will be serviceable. However, buildings subjected to temperatures above $600^{\circ} \mathrm{C}$ are structurally unsafe. At temperature above $600^{\circ} \mathrm{C}$ concrete element will have lost about $70 \%$ of its strength.

2) This investigation has affirmed that the value of UPV and RHN decreases with increasing temperature.

\section{Acknowledgements}

We hereby offer our sincere gratitude to Engr. Deji Ogundele and Engr. S.P. Akande of the Federal University of Technology Akure, for the supports provided while conducting NDT tests on the field.

\section{References}

[1]. Narendra K.G., Ray F.D. and Dilip C., Evaluation and repair of fire-damaged buildings, joint publication of the NCSEA, 2008

[2]. Jeremy I., Forensic engineering of fire damaged buildings, A journal of the Institution of Civil Engineers (ICE), paper 800040, 2009, pg. 12-17.

[3]. Awoyera P.O., Arum C. and Akinwumi I.I., Significance of Concrete Cover to Reinforcement in Structural Element at Varying Temperatures, International Journal of Scientific \& Engineering Research, 5( 6), 2014, pp. 1120 - 1123.

[4]. Arum C. and Awoyera P. O., Evaluation of Post-fire Residual Strengths of In situ Concrete and Laboratory Steel Reinforcement Samples Using Nondestructive and Destructive Test Methods" Journal of Civil Engineering, 7(1), 2011, pp.46-58.

[5]. Joseph, F.L. and James, H.P., Resistance to Fire and High Temperatures, Journal of Significance of Tests and Properties of Concrete and Concrete Making, 2002, p. 278.

[6]. Zongjin L., Advanced Concrete Technology (Hoboken, New Jersey: John Wiley \& Sons, Inc., 2011)

[7]. Cope R.J., Concrete Bridge Engineering: Performance and Advances, CRC Press, 2003, p. 29

[8]. Lawson I. et al, Non-Destructive Evaluation of Concrete using Ultrasonic Pulse Velocity, Research Journal of Applied Sciences, Engineering and Technology, 3 (6), 2011, pp. 499-504.

[9]. International Atomic Energy Agency (IAEA), Guidebook on non-destructive testing of concrete structures,. Vienna, Viewed 2nd December, 2010, <http: //wwwpub.iaea.org.>

[10]. British Standards Institution, BS 1881 part 203, Recommendation for measurement of velocity of ultrasonic pulses in concrete, 1986.

[11]. British Standards Institution, BS 1881 part 202, Recommendations for surface hardness by rebound hammer.

[12]. British Standards Institution, BS 1881 part 201, Guide to the use of nondestructive method of test for hardened concrete. 